\title{
Correction to: Silent hypoxia: higher NO in red blood cells of COVID-19 patients
}

\author{
Esmaeil Mortaz ${ }^{1}$, Majid Malkmohammad ${ }^{2 *}$, Hamidreza Jamaati ${ }^{3}$, Parisa Adimi Naghan ${ }^{3}$, \\ Seyed Mohamad Reza Hashemian ${ }^{3}$, Payam Tabarsi ${ }^{1}$, Maohammad Varahram ${ }^{4}$, Hamidreza Zaheri ${ }^{3}$, \\ Efsun Gonca Uğur Chousein ${ }^{5}$, Gert Folkerts ${ }^{6}$ and lan M. Adcock ${ }^{7,8}$
}

\section{Correction to: BMC Pulm Med 20, 269 (2020) https://doi.org/10.1186/s12890-020-01310-8}

Following publication of the original article [1], the authors reported an error concerning the affiliation of the first and the sixth author, Esmaeil Mortaz and Payam Tabarsi.

They were affiliated with the following affiliation: Mycobacteriology Research Center, National Research Institute of Tuberculosis and Lung Diseases (NRITLD), Masih Daneshvari Hospital, Shahid Beheshti University of Medical Sciences, Tehran, Iran.

While they should be affiliated with this affiliation: Clinical Tuberculosis and Epidemiology Research Center, National Research Institute of Tuberculosis and Lung Diseases (NRITLD), Shahid Beheshti University of Medical Sciences, Tehran, Iran.

The original article [1] has been updated and the corrected affiliations are provided in this article (please see the reference list above).

\section{Author details}

${ }^{1}$ Clinical Tuberculosis and Epidemiology Research Center, National Research Institute of Tuberculosis and Lung Diseases (NLRTLD), Shahid Beheshti University of Medical Sciences, Tehran, Iran. ${ }^{2}$ Tracheal Disease Research Center, National Research Institute of Tuberculosisand Lung Diseases (NRIT LD), Shahid Beheshti University of Medical Science, Tehran, Iran. ${ }^{3}$ Chronic Respiratory Diseases Research Center, National Research Institute ofTuberculosis and Lung Diseases (NRITLD), Shahid Beheshti University of Medical Sciences, Tehran, Iran. ${ }^{4}$ Mycobacteriology Research Center, National
Research Institute of Tuberculosis and Lung Diseases (NRITLD), Masih Daneshvari Hospital, Shahid Beheshti University of Medical Sciences, Tehran, Iran. ${ }^{5}$ University of Health Sciences Turkey, Yedikule Chest Diseases and Thoracic Surgery, Education and research Hospital, Department of pulmonology, Istanbul, Turkey. ${ }^{6}$ Division of Pharmacology, Utrecht Institute for Pharmaceutical Sciences, Faculty of Science, Utrecht University, Utrecht, Netherlands. ${ }^{7}$ Cell and Molecular Biology Group, Airways Disease Section, Faculty of Medicine, National Heart and Lung Institute, Imperial College London, London, UK. ${ }^{8}$ Priority Research Centre for Asthma and Respiratory Disease, Hunter Medical Research Institute, University of Newcastle, Newcastle, NSW, Australia.

Published online: 10 November 2020

Reference

1. Mortaz E, Malkmohammad M, Jamaati H, et al. Silent hypoxia: higher NO in red blood cells of COVID-19 patients. BMC Pulm Med. 2020;20:269. https:// doi.org/10.1186/s12890-020-01310-8.

The original article can be found online at https://doi.org/10.1186/s12890020-01310-8

* Correspondence: mmalekmohammad@yahoo.com

${ }^{2}$ Tracheal Disease Research Center, National Research Institute of

Tuberculosisand Lung Diseases (NRITLD), Shahid Beheshti University of

Medical Science, Tehran, Iran

(c) The Author(s). 2020 Open Access This article is licensed under a Creative Commons Attribution 4.0 International License, which permits use, sharing, adaptation, distribution and reproduction in any medium or format, as long as you give appropriate credit to the original author(s) and the source, provide a link to the Creative Commons licence, and indicate if changes were made. The images or other third party material in this article are included in the article's Creative Commons licence, unless indicated otherwise in a credit line to the material. If material is not included in the article's Creative Commons licence and your intended use is not permitted by statutory regulation or exceeds the permitted use, you will need to obtain permission directly from the copyright holder. To view a copy of this licence, visit http://creativecommons.org/licenses/by/4.0/. The Creative Commons Public Domain Dedication waiver (http://creativecommons.org/publicdomain/zero/1.0/) applies to the data made available in this article, unless otherwise stated in a credit line to the data. 